\title{
Preparation and Photonic Properties of $\mathrm{CNT} / \mathrm{TiO}_{2}$ Composites Derived from MWCNT and Organic Titanium Compounds
}

\author{
Won-Chun $\mathrm{Oh}^{\dagger}$ \\ Department of Advanced Materials \& Science Engineering, Hanseo University, Chungnam 356-706, Korea \\ (Received January 5, 2009; Revised March 16, 2009 ; Accepted March 17, 2009)
}

\begin{abstract}
In this study, $\mathrm{CNT} / \mathrm{TiO}_{2}$ composites derived from various titanium alkoxides and multiwalled carbon nanotubes (MWCNTs) were synthesized and characterized. Surface areas and pore volumes of the $\mathrm{CNT} / \mathrm{TiO}_{2}$ samples showed catastrophic decrease due to deposition of titanium compounds. Scanning electron microscopy (SEM) results indicated that the MWCNTs were homogenously decorated and well-dispersed onto/into the composites without apparent agglomeration of $\mathrm{TiO}_{2}$ particles. In the X-ray diffraction (XRD) patterns, peaks of anatase and rutile phase were observed. The energy dispersive X-ray spectroscopy (EDX) spectra revealed the presence of major elements such as $\mathrm{C}$ and $\mathrm{O}$ with strong Ti peaks. According to the photocatalytic results, MB removal by a treatment with $\mathrm{CNT} / \mathrm{TiO}_{2}$ composites seems to have an excellent removal effect as order of CTIP, CTNB and CTPP composites due to a photolysis of the supported $\mathrm{TiO}_{2}$, the radical reaction and the adsorptivity and absorptivity of the MWCNTs.
\end{abstract}

Key words: MWCNT, Titanium alkoxide, SEM, XRD, EDX, Photolysis

\section{Introduction}

C arbon nanotubes (CNTs) are remarkable materials widely studied for their extraordinary electronic and mechanical properties. With the development of CNT synthesis technology, the price of CNTs has reduced significantly and it is now possible for them to be used on a large scale. ${ }^{1)}$ Composite materials formed with CNTs have recently been the subject of particular research interest, finding use in improved high strength composites as well as in photonic and optical devices. ${ }^{2,3)}$ In the preparation of catalysts, catalyst supports and photocatalysts, a metal alkoxide is used as the starting material to avoid contamination of the inorganic counter anion from the corresponding metal salts, ${ }^{4)}$ which would affect the activity and selctivity of the catalysts. ${ }^{5,6)}$ For the purpose of encouraging heterogeneous photocatalytic oxidation for water and air purification and remediation, titania is a common and attractive alkoxide for oxide semiconductor photocatalysts because of its strong oxidizing power, absence of toxicity and long term photostability. $\mathrm{CNT} / \mathrm{TiO}_{2}$ composite derived from titanium alkoxide is an excellent cadidate for photocatalysts in the oxidation of a wide variety of organic and inorganic substances due to a combination of properties. In most preparation processes, the alkoxides are hydrolyzed in some kind of solution, yielding amorphous metal oxides with large surface areas. However,

${ }^{\dagger}$ Corresponding author: Won-Chun $\mathrm{Oh}$

E-mail : wc_ch@hanseo.ac.kr

Tel : +82-41-660-1337 Fax : +82-41-688-3352 the surface areas are drastically decreased on calcination at the temperatures where corresponding oxides begin to crystallize. Thus far, materials such as metal oxides, precious metal nanoparticles and functional organic molecules have been sucessfully decorated on CNTs through different methods. $^{7-9)}$ Several methods for the treatment of photocatalysts have been reported to improve photocatalytic efficiency. ${ }^{10,11)}$ These include increasing the surface area of composite photocatalysts, the generation of defects to induce space-charge separation, and the modification of $\mathrm{TiO}_{2}$ with metals or semiconductores. ${ }^{12-14)}$ It is expected that the combination of CNTs with titania may induce an interesting charge transfer and thus enhance the photocataltic activity of titania through leveraging the unique electronic properties of CNTs. The overall rate of the photocatalytic reaction is expressed as a function of the rates of recombination and capture of photoexcited electrons $\left(\mathrm{e}^{-}\right)$and positive holes $\left(\mathrm{h}^{+}\right)$ by substrates adsorbed on the surface. ${ }^{11,15)}$ On the basis of these findings, it has been suggested that a $\mathrm{CNT} / \mathrm{TiO}_{2}$ composite with electrical properties, high surface area and high crystallinity, which would lead to enhancement of capture and suppression of recombination, should show high photocatalytic activity. ${ }^{1)}$

In this study, a simple and effective method for the synthesis of $\mathrm{CNT} / \mathrm{TiO}_{2}$ composites derived from various titanium alkoxides and for the characterization of their influence on phase transition and photonic properties is presented. The adsorption effects, structural variations, surface state and elemental compositions of the composites were investigated through preparation of three kinds of $\mathrm{CNT}_{\mathrm{TiO}}{ }_{2}$ composites. The Brunauer-Emmett-Teller (BET) 
method, scanning electron microscopy (SEM), X-ray diffraction (XRD), energy dispersive X-ray (EDX) spectroscopy and UV/VIS spectroscopy were characterized for these new photocatalysts.

\section{Experimental Procedure}

\subsection{Materials}

Crystalline multiwalled carbon nanotube (MWCNT) powder of 95.9 wt\% purity from Carbonnano (Carbonnano Co., Ltd, Korea) were used as a starting material. Reagents (benzene, tetrahydrofuran and ethyl alcohol) were purchased at reagent-grade from Duksan Pure Chemical Co. and Daejung Chemical Co. and used without further purification, unless otherwise stated. Evaporation and concentration in vacuo were done at a water aspirator pressure with compounds dried at $1.33 \mathrm{~Pa}$. The titianium iso-propoxide (TIP, $\left.\mathrm{Ti}\left(\mathrm{OCH}\left(\mathrm{CH}_{3}\right)_{2}\right)_{4}\right)$, titanium $n$-butoxide (TNB, $\left.\mathrm{C}_{16} \mathrm{H}_{36} \mathrm{O}_{4} \mathrm{Ti}\right)$ and titanium propoxide (TPP, $\left.\mathrm{Ti}\left(\mathrm{OC}_{3} \mathrm{H}_{7}\right)_{4}\right)$ as titanium sources for the synthesis of $\mathrm{CNT} / \mathrm{TiO}_{2}$ composites were purchased at reagent-grade from Acros Organics, USA. Methylene blue $\left(\mathrm{MB}, \mathrm{C}_{16} \mathrm{H}_{18} \mathrm{~N}_{3} \mathrm{~S} \cdot \mathrm{Cl} \cdot 3 \mathrm{H}_{2} \mathrm{O}\right)$ used in this study was analytical grade and was also purchased from Duksan Pure Chemical Co., Ltd.

\subsection{Surface oxidation for the CNT}

$m$-Chloroperbenzoic acid (MCPBA, ca. $0.96 \mathrm{~g}$ ) was suspended in $60 \mathrm{~mL}$ of benzene, MWCNT (ca. $40 \mathrm{mg}$ ) was added, and the mixture was refluxed in an air atmosphere for $6 \mathrm{~h}$. The solvent was then dried at the boiling point (353.13 K) of benzene. The solid precipitates were transformed to a dark brown color. After completion, the dark brown precipitates were washed with ethyl alcohol and then dried at $363 \mathrm{~K}$. Before reaction with titanium alkoxide compounds to the oxidized MWCNT, the oxidized MWCNT was prepared.

\subsection{Synthesis of $\mathrm{CNT/TiO}{ }_{2}$ composite}

Hydrolysis and condensation reactions were performed. Oxidized CNT slurry solutions were prepared with titanium alkoxides as titanium sources and benzene for the synthesis of $\mathrm{CNT} / \mathrm{TiO}_{2}$ composites. For the synthesis, $0.5 \mathrm{~g}$ of each powdered oxidized CNT were mixed separately with titanium alkoxides as titanium sources and tetrahydrofuran (THF) aqueous solution and stirred for $6 \mathrm{~h}$ at $333 \mathrm{~K}$. Then, the mixtures were heated at $973 \mathrm{~K}$ for $1 \mathrm{~h}$ for thermal decomposition. Before heat treatment, the solvent in the mixtures was vaporized at $343 \mathrm{~K}$ for $1 \mathrm{~h}$. Finally, the samples synthesized were dried at $368 \mathrm{~K}$ for $72 \mathrm{~h}$ in an air atmosphere. The summary of the synthetic procedures and the nomenclatures for the $\mathrm{CNT} / \mathrm{TiO}_{2}$ composites are listed in Table 1.

\subsection{Characterization of $\mathrm{CNT/TiO}{ }_{2}$ composites}

For the characterization of $\mathrm{CNT} / \mathrm{TiO}_{2}$, the $\mathrm{N}_{2}$ adsorption isotherm was measured at $77 \mathrm{~K}$ using a BEL sorp Analyzer (BEL, Japan). Then, the BET surface area was calculated by nitrogen adsorption. The pore size distribution was calculated by the BJH method. SEM (JSM-5200 JOEL, Japan) was employed to observe the surface state and structure of the three kinds of $\mathrm{CNT} / \mathrm{TiO}_{2}$ composites. For the determination of the crystallographic structure of the composites, XRD patterns were taken using an X-ray generator (Shimatz XD-D1, Japan) with $\mathrm{Cu} \mathrm{K} \alpha$ radiation. EDX spectra were also used for elemental analysis of the samples. For the analysis of the photo-degradation effects, UV-VIS spectra of the $\mathrm{CNT} / \mathrm{TiO}_{2}$ composites were recorded using a Genspec III (Hitachi, Japan) spectrometer.

\subsection{Photocatalytic effect}

Photocatalytic activities were evaluated by MB degradation in aqueous media under ultraviolet light irradiation. For UV irradiation, the reaction tube was located axially and held in the UV lamp (20 W, $365 \mathrm{~nm}$ ) box. The lamp was used at a distance of $100 \mathrm{~mm}$ from the solution in the dark box. The initial MB concentration $\left(\mathrm{c}_{0}\right)$ was $1.0 \times 10^{-5} \mathrm{~mole} / \mathrm{L}$. The suspension containing the $\mathrm{MB}$ and $\mathrm{CNT} / \mathrm{TiO}_{2}$ composites was stirred with an ultrasonicator in darkness for $3 \mathrm{~min}$ to establish an adsorption-desorption equilibrium. The amount of suspended $\mathrm{CNT} / \mathrm{TiO}_{2}$ composites was kept at $0.005 \mathrm{~g} / \mathrm{mL}$. The suspension was irradiated with ultraviolet (UV) light as a function of irradiation time. Samples were then withdrawn regularly from the reactor and dispersed powders were removed through centrifugation. The clean transparent solution was analyzed by UV/VIS spectroscopy. The concentration of MB in the solution was determined as a function of irradiation time from the absorbance region at a wavelength line of $256 \mathrm{~nm}$.

\section{Results and Discussion}

\subsection{Physico-chemical and surface properties}

The $\mathrm{CNT} / \mathrm{TiO}_{2}$ composite catalysts derived from various organic titaniun sources and MWCNTs were noted as CTIP, CTNB and CTPP. Nitrogen adsorption isotherms for the original MWCNT and $\mathrm{CNT} / \mathrm{TiO}_{2}$ composites are shown in

Table 1. Nomenclatures of $\mathrm{CNT} / \mathrm{TiO}_{2}$ Composites Prepared with Different Organic Titanium Sources

\begin{tabular}{cc}
\hline Preparation method & Nomenclatures \\
\hline Carbon Nanotube+Titanium Isoproxide (TIP & \\
$(99.99 \%), 10 \mathrm{~mL})+$ Tetra Hydrofuran (THF & CTIP \\
$(99.8 \%), 10 \mathrm{~mL})$ & \\
Carbon Nanotube+Titanium n-butoxide (TNB & \\
$(99.99 \%), 10 \mathrm{~mL})+$ Tetra Hydrofuran (THF & CTNB \\
$(99.8 \%), 10 \mathrm{~mL})$ & \\
Carbon Nanotube+ Titanium Propoxide (TPP & \\
$(99.99 \%), 10 \mathrm{~mL})+$ Tetra Hydrofuran (THF & CTPP \\
$(99.8 \%), 10 \mathrm{~mL})$ & \\
\hline
\end{tabular}


Fig. 1. The formation of Type II adsorption isotherms confirmed the major presence of micropores and the minor presence of mesopores on the surface of the CTIP, CTNB and CTPP. This indicates that the $\mathrm{CNT} / \mathrm{TiO}_{2}$ composites studied were mainly micro- and mesoporous in character, with a minor presence of wider pores where capillary condensation occurred. ${ }^{16)}$ The slight increase of adsorption is observed at relative pressures lower than 0.1. Each isotherm shows a tiny knee band region, which is characteristic of small microporous adsorbents. This phenomenon is associated with pore filling by capillary condensation in micropores. The end of the knee band in each isotherm also occurs at a relative pressure of approximately 0.1 . All of the isotherm shapes show similar types for all $\mathrm{CNT}_{\mathrm{TiO}}$ samples. Table 2 compares the textural properties of the CNT/ $\mathrm{TiO}_{2}$ samples and their microstructure changes with those of the original MWCNTs. Surface areas and pore volumes of the $\mathrm{CNT} / \mathrm{TiO}_{2}$ samples were catastrophically reduced due to deposition of titanium compounds. The increase of average pore diameter of the $\mathrm{CNT} / \mathrm{TiO}_{2}$ samples was attributed to the increase of the amount of mesopores resulting from calcination at $700^{\circ} \mathrm{C}$. The BET surface area of the MWCNT was $232.17 \mathrm{~m}^{2} / \mathrm{g}$, which decreased greatly to about $84.06 \sim 3.901 \mathrm{~m}^{2} / \mathrm{g}$ when the CTIP, CTNB and CTPP composites were formed. The pore size distributions for the original MWCNT and $\mathrm{CNT} / \mathrm{TiO}_{2}$ samples are shown in Fig. 2. All $\mathrm{CNT} / \mathrm{TiO}_{2}$ samples presented a large number of pores in the broad pore distribution range of $0.4 \sim 0.8 \mathrm{~nm}$, and a small number of mesopores appeared due to the introduction of titanium compounds. Compared with the original MWCNT sample, the mesopore volume of all $\mathrm{CNT} / \mathrm{TiO}_{2}$ samples decreased as order of CTIP, CTNB and CTPP composites. Generally, the BET surface areas of the porous carbon matrix used in the preparation of carbon-titania composites are considerably decreased due to a blocking of the narrow pores by surface complexes introduced by titanium sources. ${ }^{17,18)}$

The morphology and micro-surface structure of the CNT/ $\mathrm{TiO}_{2}$ composites derived from different organic titanium sources were characterized by SEM and FE-SEM. The changes in the morphology of the MWCNT-based composites that occurred as a result of the experiment are shown in Fig. 3. It seems that CNT introduced into $\mathrm{TiO}_{2}$ can prevent $\mathrm{TiO}_{2}$ particles from agglomerating. This result is also confirmed by FE-SEM inspection of the $\mathrm{CNT} / \mathrm{TiO}_{2}$ composite materials. The images present an overall view of CNTs that were introduced into the $\mathrm{TiO}_{2}$, which had external diameters ranging from 0.5 to $1.0 \mu \mathrm{m}$. These large CNT islands consist of clusters of composites. Moreover, Fig. 3(f) indicates that the $\mathrm{TiO}_{2}$ components entirely covered the dispersed CNT islands in the $\mathrm{CNT} / \mathrm{TiO}_{2}$ composite. The surface morphology of the composites determined from SEM and FE-SEM images shows different surface states for each of the samples, which clearly illustrates that the MWCNTs were homogenously decorated and well-dispersed onto/into the composites without apparent agglomeration of $\mathrm{TiO}_{2}$ par-

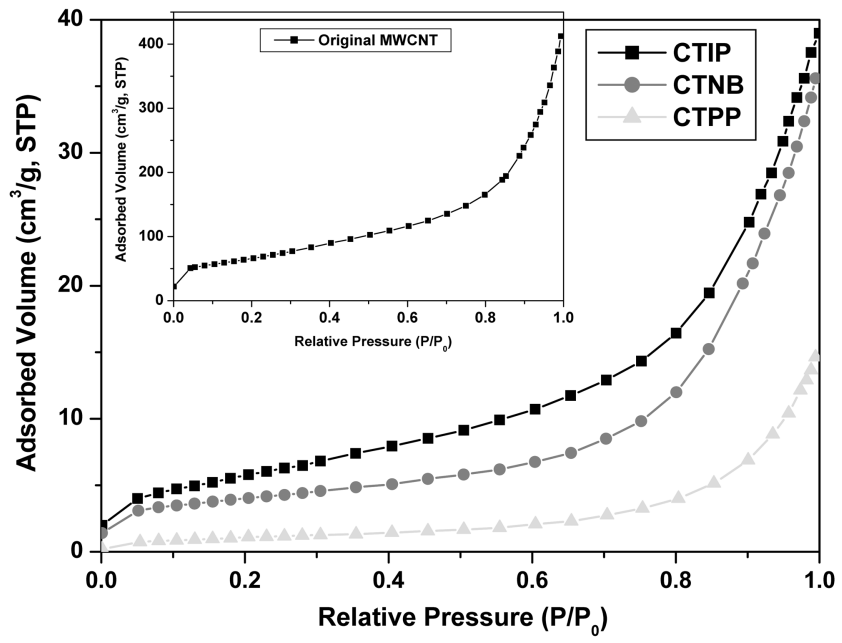

Fig. 1. Nitrogen adsorption isotherms obtained from the original MWCNT and $\mathrm{CNT} / \mathrm{TiO}_{2}$ composites.

Table 2. Textural Properties of Original MWCNT and $\mathrm{CNT} / \mathrm{TiO}_{2}$ Composite Samples

\begin{tabular}{cccc}
\hline & \multicolumn{3}{c}{ Parameter } \\
\cline { 2 - 4 } Sample & $\begin{array}{c}\mathrm{S}_{\mathrm{BET}} \\
\left(\mathrm{m}^{2} / \mathrm{g}\right)\end{array}$ & $\begin{array}{c}\text { Micropore } \\
\text { Volume } \\
\left(\mathrm{cm}^{3} / \mathrm{g}\right)\end{array}$ & $\begin{array}{c}\text { Average Pore } \\
\text { Diameter }(\mathrm{nm})\end{array}$ \\
\hline $\begin{array}{c}\text { Original } \\
\text { MWCNT }\end{array}$ & 232.17 & 0.5504 & 0.948 \\
CTIP & 84.061 & 0.1071 & 0.509 \\
CTNB & 21.788 & 0.0406 & 0.776 \\
CTPP & 3.901 & 0.0106 & 1.09 \\
\hline
\end{tabular}

ticles. The high magnification images for the CTPP sample derived by thermal decomposition with TPP show a particularly homo- genous appearance and smoothly aligned lattice fringes with only individual MWCNTs in the composites without any jam-like aggregates. The good dispersion of small MWCNT particles throughout the composites could provide information on the existence of more effective reactive sites, as a considerable portion of $\mathrm{TiO}_{2}$ would be enclosed in the three-dimensional matrix.

\subsection{Structural and chemical components}

The XRD patterns of the three kinds of samples derived from MWCNT and titanium sources desolved in THF are shown in Fig. 4, and demonstrate the highly crystalline nature of the composites. The major peaks at 25.3, 37.8, $48.0,53.8,54.9$ and 62.5 correspond to diffractions of (101), (004), (200), (105), (211) and (204) reflections of anatase, which suggests that the $\mathrm{TiO}_{2}$ particles decorated with MWCNT agglomerates are anatase. The XRD results indicate that the phase transition from organic titanium sources to anatase phase has taken place at heat treatment temperature $(973 \mathrm{~K})$, with formation of titania crystalline. 


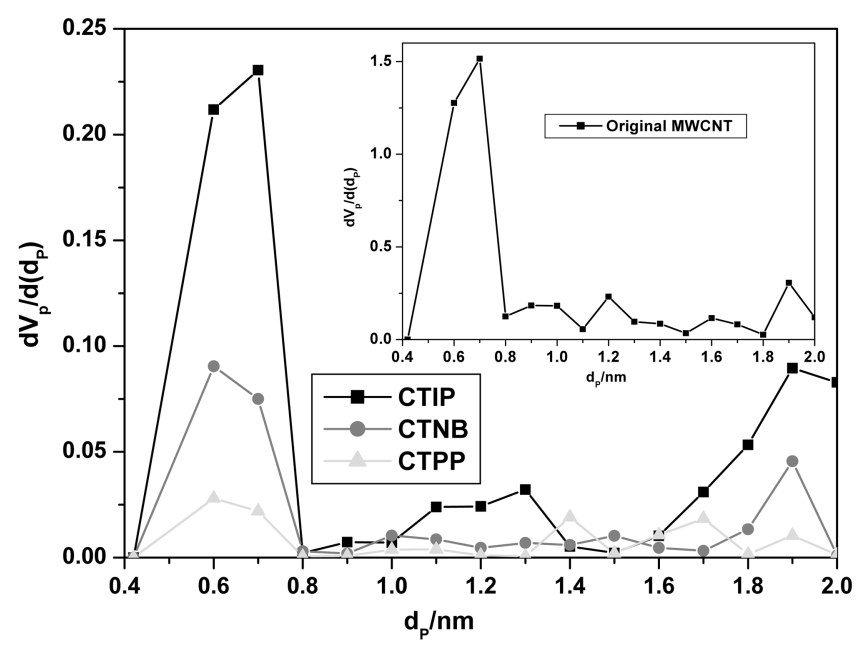

Fig. 2. Comparison of pore size distribution for the original MWCNT and CNT/TiO 2 composites.

This indicates that the precursors, organic titanium compounds, were converted to anatase. However, the diffraction peaks of the MWCNTs were not clearly observed due to the high $\mathrm{TiO}_{2}$ contents and the high crystallinity, as has been reported in the literature. ${ }^{19,20)}$ The strength of the anatase diffraction peaks of the CTIP sample was more intense than that of the other samples, and the outline of the diffraction peaks was accurate for all of the samples, indicating that the heat treatment temperature $(974 \mathrm{~K})$ was helpful to improve the degree of crystallinity in the titanium organic sources. Of the two crystal forms of $\mathrm{TiO}_{2}$ catalysts, the anatase invariably exhibits a higher photoactivity than the rutile dose. ${ }^{21,22)}$ The results from Kominami et $a l^{23)}$ showed that the XRD patterns of $\mathrm{TiO}_{2}$ derived from titanium alkoxide in organic solvents consistently presented the formation of anatase crystallites at low temperatures. However, with an increase of the heat treatment temperature, the patterns showed the presence of mixtures of anatase and rutile structures. In the present study, another crystalline phase presented the rutile phases of (110), (101), (200), (211), (220), (311), and (112) at peaks of 28.1, 37.0, 89.1, 53.2, 55.2, 67.8 and 69.2, indicating that the $\mathrm{TiO}_{2}$ prepared existed in the anatase and rutile mixture states. The fact that the titanium sources are included in the phase formation is considered significant, due to differences of thermal energy for the dehydration and crystallization of $\mathrm{TiO}_{2}$ formation.

Additionally, quantitative EDX spectra analyses of CNT/ $\mathrm{TiO}_{2}$ composites derived from MWCNT and titanium sources dissolved in THF were confirmed using EDX. The spectra obtained from the $\mathrm{CNT} / \mathrm{TiO}_{2}$ composites are shown in Fig. 6. The spectra indicate the presence of $\mathrm{C}, \mathrm{O}$ and $\mathrm{Ti}$ as major elements, along with minor metallic impurity components. Notably, the numerical result of a quantitative EDX microanalysis of the CTNB yielded a component ratio of 18.54: 42.46:36.13 for C:Ti:O. However, the results of CTIP and CTPP cases decreased for the Ti component with an increase of the $\mathrm{C}$ component. For most of the samples, C,

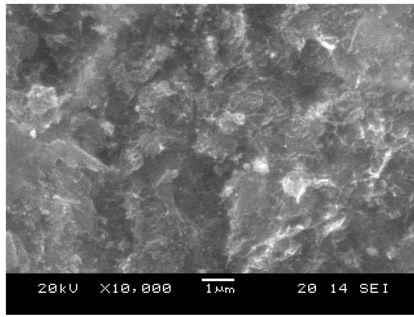

(a)

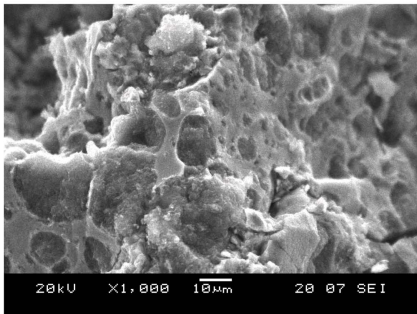

(c)

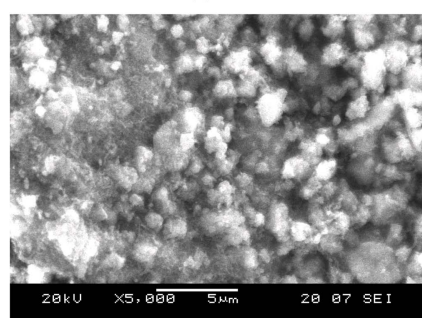

(e)

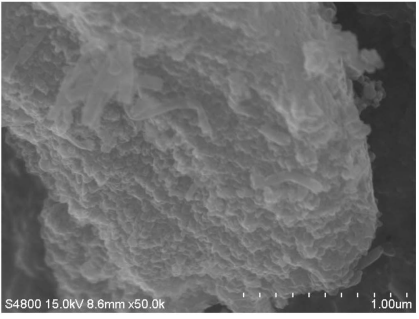

(b)

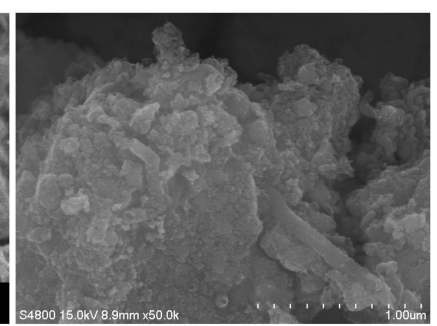

(d)

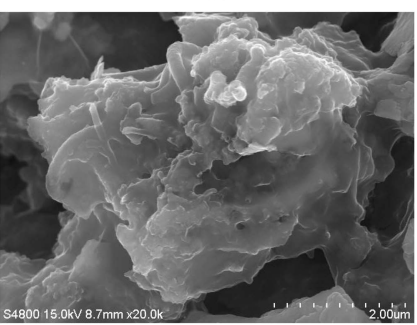

(f)
Fig. 3. SEM and FE-SEM micrographs for the $\mathrm{CNT} / \mathrm{TiO}_{2}$ composites ; (a) CTIP (over-all scale), (b) CTIP (closeup), (c) CTNB (over-all scale), (d) CTNB (close-up), (e) CTPP (over-all scale), and (f) CTPP (close-up).

$\mathrm{Ti}$ and $\mathrm{O}$ were present as major elements in the $\mathrm{CNT} / \mathrm{TiO}_{2}$ composites. The results of the EDX elemental microanalysis (wt\%) of the $\mathrm{CNT} / \mathrm{TiO}_{2}$ composites are listed in Table 3.

\subsection{Photocatalytic effect of $M B$}

The photodegradation studies in aqueous supension containing $\mathrm{CNT} / \mathrm{TiO}_{2}$ composite catalyst showed that three kinds of the tested samples could photocatalyze the degradation of MB. Fig. 7 shows the changes of the absorbance after a color removal process in the relative $\mathrm{MB}$ degradation concentration using the $\mathrm{CNT} / \mathrm{TiO}_{2}$ composites under UV light irradiation. This change of the absorbance for the MB degradation with $\mathrm{CNT}_{\mathrm{TiO}}$ photocatalysts was used to measure the photolysis effect under UV light. The measurement of the absorbance maxima $\left(\lambda_{\max }\right)$ value in the spectra with decomposed MB products was tried as a function of the degradation time against the $\mathrm{CNT} / \mathrm{TiO}_{2}$ photocatalysts. It showed that the $\lambda_{\max }$ values moved to a lower absorbance region with an increase of the irradiation time. According to previous studies, ${ }^{24-26)}$ it has been observed that the intensity of the $\lambda_{\max }$ values measured as a function of the irradiation time depends on the concentration of organic dyes. The formation of $\lambda_{\max }$ was proportional to the concentration decrease of the transient formed after UV light excitation. The absorbance level defining the $\lambda_{\max }$ values for the MB 


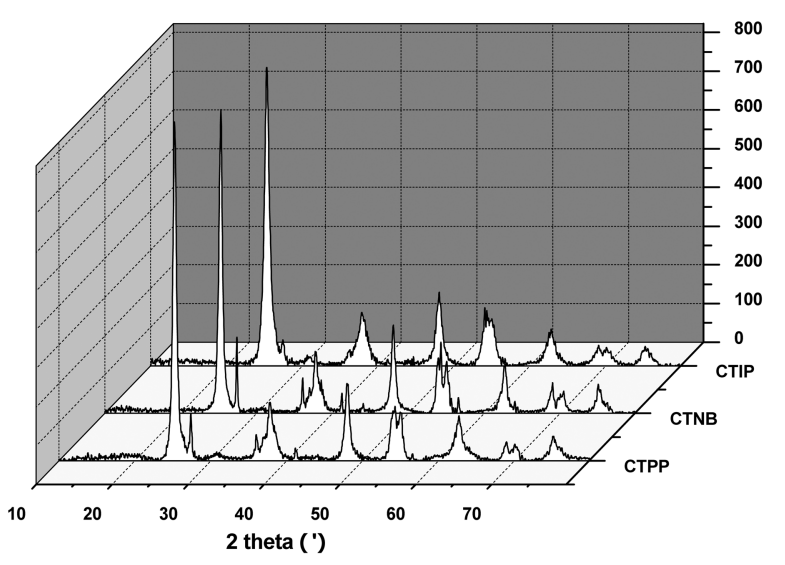

Fig. 4. XRD patterns of the $\mathrm{CNT} / \mathrm{TiO}_{2}$ composites deriverd from MWCNTs and various organic titanium sources.

Table 3. EDX Elemental Microanalyses of $\mathrm{CNT} / \mathrm{TiO}_{2}$ Composites

\begin{tabular}{cccccccc}
\hline Sample & $\mathrm{C}$ & $\mathrm{O}$ & $\mathrm{Ti}$ & $\mathrm{V}$ & $\mathrm{Cu}$ & $\mathrm{Zn}$ & Total \\
\hline CTIP & 41.89 & 31.59 & 23.65 & 0.41 & 1.47 & 0.98 & 100.00 \\
CTNB & 18.54 & 36.13 & 42.46 & 1.25 & 0.75 & 0.88 & 100.00 \\
CTPP & 42.71 & 30.32 & 25.43 & 0.45 & 0.63 & 0.45 & 100.00 \\
\hline
\end{tabular}

decomposed by the CTPP sample was higher than that of the MB decomposed by the CTIP and CTNB samples. It is considered that the sharp decrease in the $\lambda_{\max }$ values of absorbance can be attributed to a degradative reaction. In Fig. 8, the changes of relative concentration $\left(\mathrm{c} / \mathrm{c}_{0}\right)$ against time function $(f(t))$ are shown by the photocatalytic degradation of $\mathrm{MB}$ in the aqueous solution containing $\mathrm{CNT} / \mathrm{TiO}_{2}$ composite photocatalysts under UV light irradiation. The kinetic rates by color removal are presented on the $c / c_{0}$ of MB degraded in the aqueous solution as a function of UV irradiation time. These results indicate that the standard organic dye (MB) solution is quite unstable with variation of concentration under UV light irradiation with $\mathrm{CNT} / \mathrm{TiO}_{2}$ composites. The plots for the relationship between the $\mathrm{c} / \mathrm{c}_{0}$ and time function for the MB solution products show mild curve properties due to the combination of the presence of UV light and an oxidation effect in the suspension. Generally, MWCNTs had a semiconducting effect with an increase of charge transfer. It is considered that the decomposition of organic dye in the aqueous solution occurs in two synergentic effects such as photodecomposition and quantum efficiency. This suggests that the $\mathrm{CNT} / \mathrm{TiO}_{2}$ composites combined the features of MWCNTs and $\mathrm{TiO}_{2}$, generating new properties that would be favorable to widening absorption from the UV light region to the visible light region. The photodegradation effect of $\mathrm{MB}$ in an aqueous suspension containing $\mathrm{CNT} / \mathrm{TiO}_{2}$ composite could be considered to the homogeneous aggregation between MWCNT and $\mathrm{TiO}_{2}$ aggregates, which may be greatly different from the mixture of MWCNT and $\mathrm{TiO}_{2}$. The intensities of these peaks

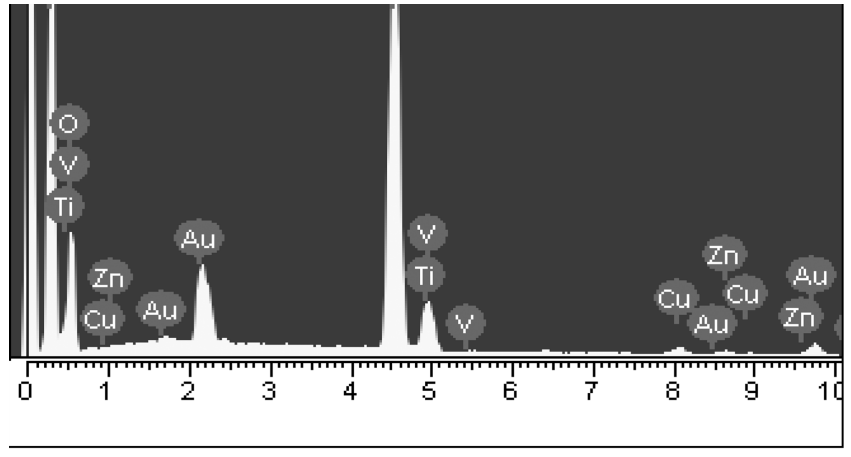

(a)

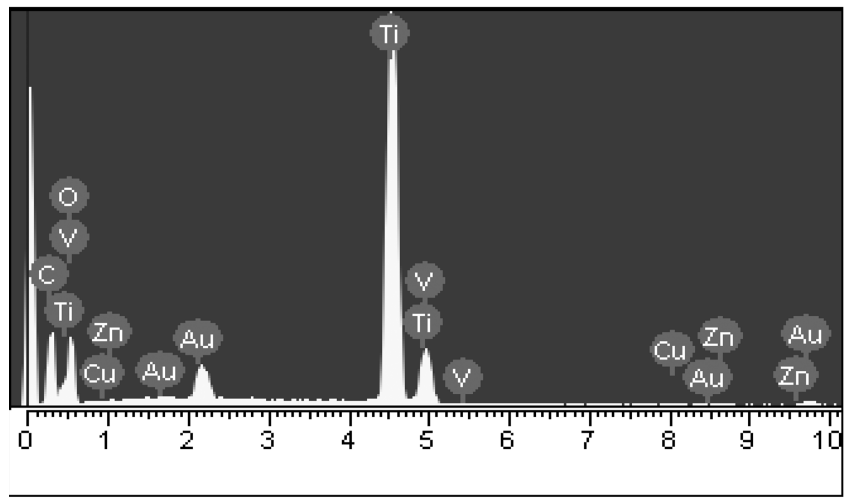

(b)

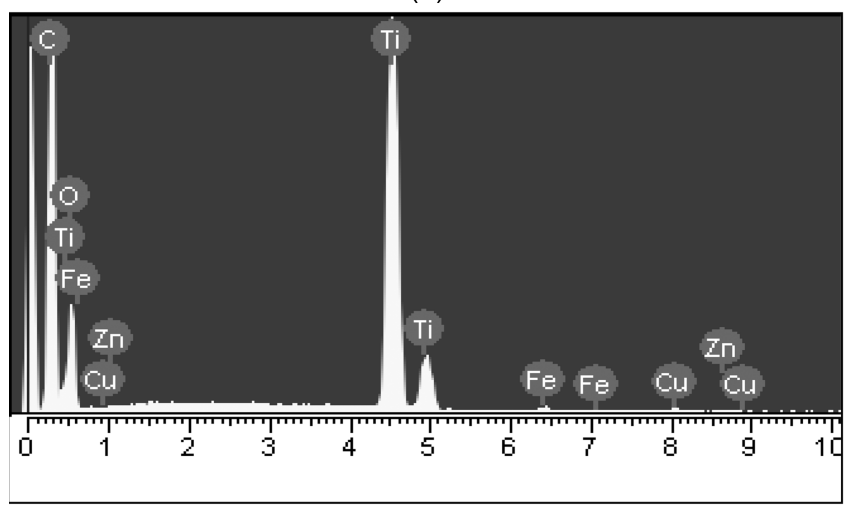

(c)

Fig. 5. EDX elemental microanalysis for the $\mathrm{CNT} / \mathrm{TiO}_{2}$ composites; (a) CTIP, (b) CTNB, and (c) CTPP.

decline with the increase of time. Moreover, the peaks at $610 \mathrm{~nm} \sim 620 \mathrm{~nm}$ for dyes indicate the presence of nitro compounds or aryl, which become weak as time increases. The synergetic effects between MWCNT and $\mathrm{TiO}_{2}$ could be ascribed to the enhanced photocatalytic decomposition of the dye on $\mathrm{CNT} / \mathrm{TiO}_{2}$ composites due to transfer through an interphase to titania. The characteristics of the synergetic effects of the two components for the dye decomposition have been introduced to the effects between photocatalysis of the supported $\mathrm{TiO}_{2}$ and the adsorptivity of the carbons. ${ }^{24,27-29)}$

From the MB solution decomposed over $60 \mathrm{~min}$ at the initial MB concentration (at $1.0 \times 10^{-5} \mathrm{~mol} / l$ ), it can be seen that the relative concentration for the CTPP results in a more significant degradation effect with a decrease of $c / c_{0}$ values 


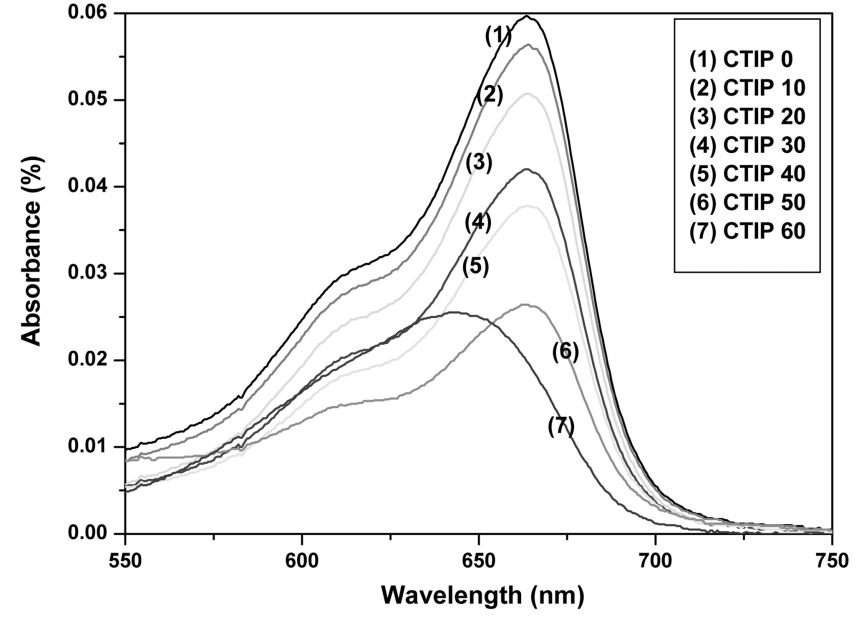

(a)

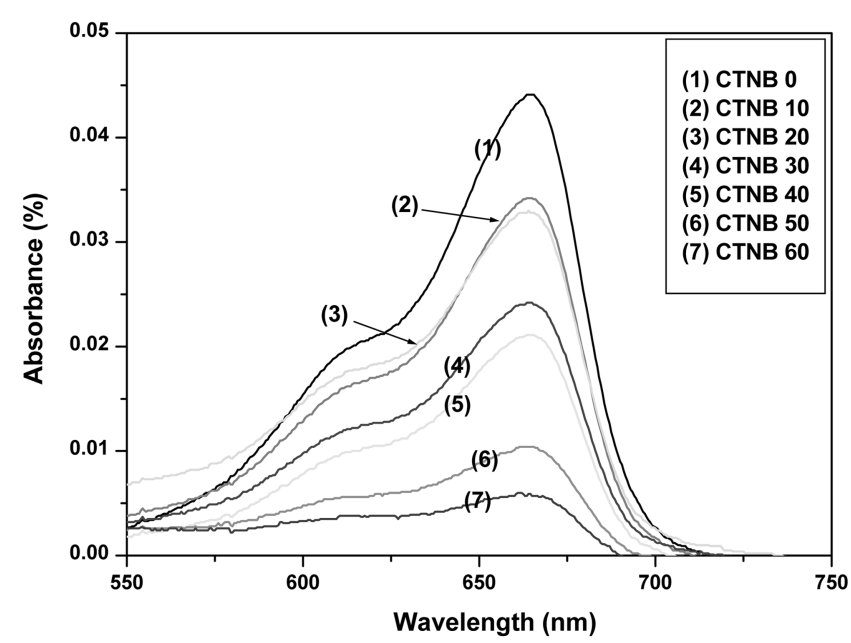

(b)

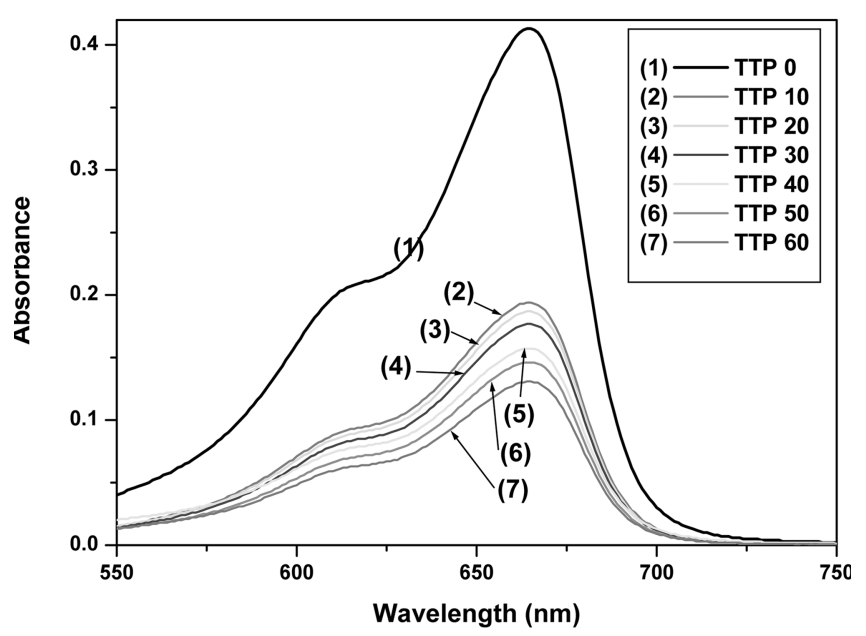

(c)

Fig. 6. UV/VIS spectra of MB concentration against the CNT/ $\mathrm{TiO}_{2}$ composites under various irradiation time conditions; (a) CTIP, (b) CTNB, and (c) CTPP.

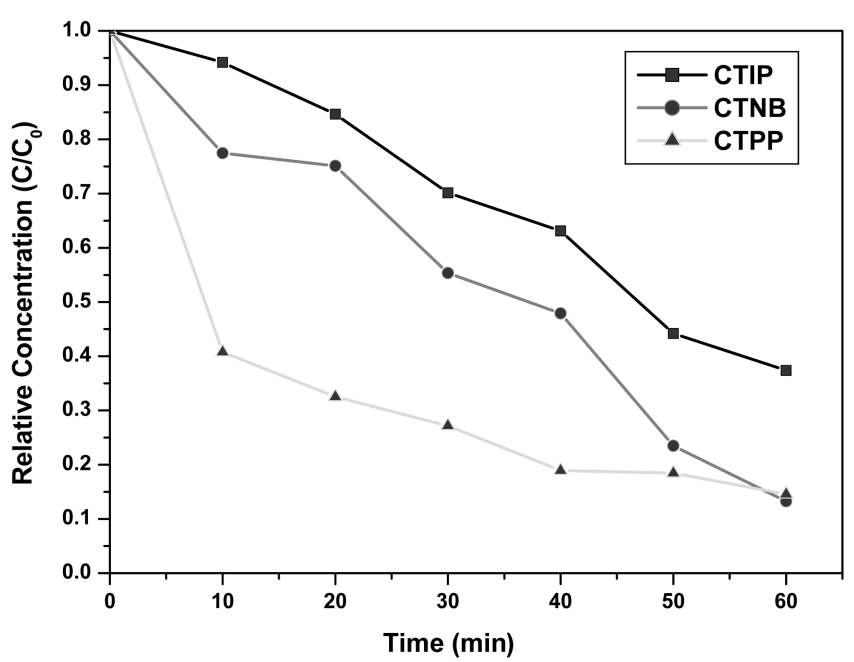

Fig. 7. Dependence of relative concentration of $\mathrm{MB}$ in the aqueous solution $\mathrm{C} / \mathrm{C}_{0}$ on $\mathrm{UV}$ irradiation time for the $\mathrm{CNT} / \mathrm{TiO}_{2}$ composites derived from the different organic titanium compounds.

than occurs for the CTNB or CTIP. As shown in Fig. 8, the fluctuation of the CTPP curve decreases almost two times as much as that of the CTNB curve, which means that this difference is due to the initial adsorption rate of the MB compound by the CNT component in the $\mathrm{CNT}^{\mathrm{T}} \mathrm{TiO}{ }_{2}$ composite materials. It was shown that the fluctuation of reaction over the photocatalytic effect of CTPP after UV irradiation is much smaller than that of the other cases. It can be considered that the photocatalytic decomposition of pollutants occurs on $\mathrm{TiO}_{2}$ particles, on those aggregated and coated MWCNTs in the $\mathrm{TiO}_{2}$. The semiconducting properties of MWCNTs have been introduced the indubitable interaction between MWCNT and $\mathrm{TiO}_{2}{ }^{30,31)}$ which may have led to the higher catalytic activity by the process of the electron/hole pair formation under light irradiation. From the results of MB degradation over $50 \mathrm{~min}$, it was shown that the kinetics plots for the $\mathrm{CNT} / \mathrm{TiO}_{2}$ samples result in a more significant degradation effect with an increase in $\left(\mathrm{c} / \mathrm{c}_{0}\right)$ values than that of the original $\mathrm{TiO}_{2}{ }^{32}$ and $\mathrm{P}-25{ }^{33)}$ According to an earlier study ${ }^{34)}$ it is force to excellent photocatalytic effects for the $\mathrm{CNT}_{\mathrm{TiO}} \mathrm{T}_{2}$ composite due to an increasing of electron transfer effects from the CNT surface to the $\mathrm{TiO}_{2}$. MWCNTs acting as electron sensitizers and donators in the composite photocatalysts may accept the electron $\left(\mathrm{e}^{-}\right)$photo-induced by light irradiation. The electrons in MWCNTs may be transferred into the conduction band in the $\mathrm{TiO}_{2}$ particles. It is considered that photo-induced charge transfer occurs in the electronic interaction between the carbon layers or walls of the MWCNTs and the $\mathrm{TiO}_{2}$. The electrons formed by light irradiation on the surface of MWCNTs migrate to the surface of the $\mathrm{TiO}_{2}$ and thus lead to a higher rate of reduction in the $\mathrm{e} / \mathrm{h}^{+}$pair recombination and to an increase of the photon efficiency, which reduces the quantum yield of the $\mathrm{TiO}_{2}$ catalyst. The light absorption capability of the photocatalyst and the separation of photogenerated $\mathrm{e}^{-} / \mathrm{h}^{+}$pairs are crucial 
factors influencing the photoactivity. CNT materials have one-dimensional carbon-based ideal molecules with the nanocylinders, in which the electrons can be considered as moving freely through the walls of the nanotubes. ${ }^{35)}$ Accordingly, it is more reasonable to ascribe that the electron absorptionability of $\mathrm{TiO}_{2}$ decorated with MWCNTs greatly increases due to the more active sites available on the surface of MWCNTs. Considering the semiconducting property of a MWCNT, it may absorb the irradiation and inject the photo-induced electron into the $\mathrm{TiO}_{2}$ conduction band. These electrons in the conduction band may react with $\mathrm{O}_{2}$, which can trigger the formation of a very reactive superoxide radical ion $\left(\mathrm{O}_{2}^{-}\right)$. Simultaneously, a positively charged hole $\left(\mathrm{h}^{+}\right)$might be formed with the electron transfer from the valence bond in the $\mathrm{TiO}_{2}$ to the MWCNTs. The positively charged hole $\left(\mathrm{h}^{+}\right)$may react with the $\mathrm{OH}^{-}$derived from $\mathrm{H}_{2} \mathrm{O}$, which can trigger the formation of a hydroxyl radical (HO ). Consequently, these radical groups are responsible for the decomposition of the organic compounds.

\section{Conclusion}

This study has presented the preparation and characterization of $\mathrm{CNT} / \mathrm{TiO}_{2}$ composites synthesized from various organic titanium sources and MWCNT. The adsorption and surface properties as well as the structural and chemical composition of the $\mathrm{CNT} / \mathrm{TiO}{ }_{2}$ composites were investigated. Surface areas and pore volumes of the $\mathrm{CNT} / \mathrm{TiO}$, samples were catastrophically reduced due to deposition of titanium compounds. From the SEM results, it was found that the MWCNTs were homogenously decorated and well-dispersed onto/into the composites without apparent agglomeration of the $\mathrm{TiO}_{2}$ particles. The peaks of anatase and rutile phase were clearly observable in the XRD diffraction patterns. The EDX spectra revealed the presence of major elements such as $\mathrm{C}$ and $\mathrm{O}$ with strong Ti peaks. According to the photocatalytic results, $\mathrm{MB}$ removal by a treatment with $\mathrm{CNT} / \mathrm{TiO}_{2}$ composites seems to have an excellent removal effect as order of CTIP, CTNB and CTPP composites. It can be concluded that the decomposition of standard organic dye on the $\mathrm{CNT} / \mathrm{TiO}_{2}$ composites proceeded by synergetic effects such as radical, photocatalytic reactions and adsorption.

\section{Acknowledgment}

This work was supported by the Research Foundation of Hanseo University in 2008. The authors are grateful to staff at Hanseo University for financial support.

\section{REFERENCES}

1. Y. Yu, J.C. Yu, C.Y. Chan, Y.K. Che, J.C. Zhao, and L. Ding, "Enhancement of Adsorption and Photocatalytic Activity of $\mathrm{TiO}_{2}$ by using Carbon Nanotubes for the Treatment of Azo Dye," Appl. Cat. B: Environ., 61 1-11 (2005).

2. S.M. Yuen, C.C. Ma, C.Y. Chung, Y.H. Hsiao, C.L. Ching, and A.D. Yu, "Preparation, Morphology and Electrical Properties of $\mathrm{TiO}_{2}$ Coated Multiwalled Carbon Nanotube/ epoxy Composites," Composites: Part A, 39 119-23 (2008).

3. R. Ulbricht, S.B. Lee, X. Jiang, K. Inoue, M. Zhang, S. Fang, R.H. Baughman, and A.A. Zakhidov, "Transparent Carbon Nanotube Sheets as 3-D Charge Collectors in Organic Solar Cells," Solar Energy Materials and Solar Cells, 91 [5] 416-19 (2007).

4. N.B. Jackson, S.G. Thoma, S. Kohler, and T. M. Nenoff, "Zirconium-titanium Phosphate Acid Catalysts Synthesized by Sol Gel Techniques," Studies in Surface Science and Catalysis, 118 643-49 (1998).

5. G. Zhang, L. Wang, K. Shen, D. Zhao, and H. S. Freeman, "Hydrogenation of o-chloronitrobenzene on a $\mathrm{Pd} / \mathrm{C}$ Catalyst Doped with Metal Oxide Nanoparticles," Chemical Engineering J., 141 [1-3] 368-74 (2008).

6. S. Yang, W. Zhu, J. Wang, and Z. Chen, "Catalytic Wet Air Oxidation of Phenol Over $\mathrm{CeO}_{2}-\mathrm{TiO}_{2}$ Catalyst in the Batch Reactor and the Packed-bed Reactor," J. Hazardous Materials, 153 [3] 1248-53 (2008).

7. P.M. Ajayan, "Nanotubes from Carbon," Chem. Rev., 99 [7] 1787-92 (1999).

8. R.H. Baughman, A.A. Zakhidov, and W.A. de Heer, "Carbon Nanotubes-the Route Toward Applications," Science, 297 [5582] 787-92 (2002).

9. P. Vincent, A. Brioude, C. Journet, S. Rabaste, S.T. Purcell, J. Le Brusq, and J.C. Plenet, "Inclusion of Carbon Nanotubes in a $\mathrm{TiO}_{2}$ Sol-gel Matrix," J. Non-Crystalline Solids, 311 130-37 (2002).

10. W.C. Oh, A.R. Jung, and W.B. Ko, "Preparation of Fullerene/ $\mathrm{TiO}_{2}$ Composite and its Photocatalytic Effect," $J$. Industrial and Engineering Chemistry, 13 [7] 1208-14 (2007).

11. W.C. Oh and M.L. Chen, "Synthesis and Characterization of CNT/TiO 2 Composites Thermally Derived from MWCNT and Titanium (IV) n-butoxide," Bull. Kor. Chem. Soc., 29 [1] 159-64 (2008).

12. W.C. Oh, and M.L. Chen, "Electro-chemical Preparation of $\mathrm{TiO}_{2} / \mathrm{ACF}$ Composites with TNB Electroyte and Their Photocatalytic Effect," J. Ceramic Processing Research, 9 [2] 100-06 (2008).

13. S.H. Chien, Y. C. Liou, and M.C. Kuo, "Preparation and Characterization of Nonosized Pt/Au Particles on $\mathrm{TiO}_{2}$-nanotubes," Synthetic Metals, 152 333-36 (2005).

14. D. He, L. Yang, S. Kuang, and Q Cai, "Fabrication and Catalytic of $\mathrm{Pt}$ and $\mathrm{Ru}$ Decorated $\mathrm{TiO}_{2} / \mathrm{CNTs}$ Catalyst for Methanol Electrooxidation," Elctrochemistry Communications, 9 2467-72 (2007).

15. W. Wang, P. Serp, P. Kalck, and J.L. Faria, "Visible Light Photodegradation of Phenol on MWCNT-TiO 2 Composite Catalysts Prepared by a Modified Sol-gel Method," J. Molecular Catalysis A: Chemical, 235 194-99 (2005).

16. J.W. Patrick, "Porocity in Carbon Characterization and Applications," pp. 28-30, Edward Arnold, London, 1995.

17. M.L. Chen, Y.S. Ko, and W.C. Oh, "Carbon/ $/ \mathrm{TiO}_{2}$ Prepared from to Pitch and their Photocatalytic Activity", Carbon Science, 8 [1] 6-11 (2007).

18. W.C. Oh, Synthesis and Characterization of Fe-containing $\mathrm{AC} \mathrm{TiO}_{2}$ Composites and their Photodegradation Effect for the Piggery Waste, Environ. Eng. Res., 13 [2] 85-92 (2008). 
19. X.H. Xia, Z.J. Jia, Y. Yu, Y. Liang, Z. Wang, and L.L. Ma, "Preparation of Multi-walled Carbon Nanotube Supported $\mathrm{TiO}_{2}$ and its Photocatalytic Activity in the Reduction of $\mathrm{CO}_{2}$ with $\mathrm{H}_{2} \mathrm{O}$," Carbon, 45 717-21 (2007).

20. A. Jitianu, T. Cacciaguerra, R. Benoit, S. Delpeux, F. Beguin, and S. Bonnamy, "Synthesis and Characterization of Carbon Nanotubes-TiO ${ }_{2}$ Nanocomposites," Carbon, 42 1147-51 (2004).

21. M.L. Chen, J.S. Bae and W.C. Oh, "Photocatalytic Effect for the Carbon-coated $\mathrm{TiO}_{2}$ Prepared from Different Heat Treatment Temperature," Analytical Science \& Technology, 19 [6] 460-67 (2006).

22. W.C. Oh, J.S. Bae, and M.L. Chen, "Preparation of Carboncoated $\mathrm{TiO}_{2}$ at Different Heat Treatment Temperatures and their Photoactivity," Carbon Science, 7 [4] 259-65 (2006).

23. H. Kominami, J. Kato, Y. Takada, Y. Doushi, B. Ohtani, S. Nishimoto, M. Inoue, T. Inui, and Y. Kera, "Novel Synthesis of Microcrystalline Titanium(IV) Oxide Having High Thermal Stability and Ultra-high Photocatalytic Activity: Thermal Decomposition of Titanium(IV) Alkoxide in Organic Solvents," Catalysis Latters, 46 235-40 (1997).

24. W.C. Oh, and A.R. Jung, "Properties and Photocatalytic Activity of Pitch-binded $\mathrm{ACF}^{\mathrm{T}} \mathrm{TiO}{ }_{2}$ Composites," J. Kor. Ceram. Soc., 45 [3] 150-56 (2008).

25. W.C. Oh, and Y.R. Na, "Photocatalytic Oxidation for Organic Dye using Phenol Resin-based Carbon-titania Composites," J. Kor. Ceram. Soc., 45 [1] 36-42 (2008).

26. W.C. Oh, and T.S. Park, "Comparative Analysis of the Physical Properties and Photocatalytic Effects for $\mathrm{C} / \mathrm{TiO}_{2}$ Complexes Derived from Titanium n-butoxide," Environ. Eng. Res., 12 [5] 218-23 (2007).

27. W.C. Oh, S.B. Han, and J.S. Bae, "The Analysis for the $\mathrm{HCl}$ Modification Effect and Formation of $\mathrm{TiO}_{2}$ on Activated
Carbon Fiber Surface," Analytical Science \& Technology, 20 [4] 279-88 (2007).

28. Z.S. Guan, X.T. Zhang, Y. Ma, Y.A. Cao, and J. N. Yao, "Photocatalytic Activity of $\mathrm{TiO}_{2}$ Prepared at Low Temperature by a Photo-assisted Sol-gel Method," J. Mater. Res., 16 [4] 907-09 (2001).

29. M. Inagaki, Y. Hirose, T. Matsunage, T. Tsumura, and M. Toyoda, "Carbon Coating of Anatase-type $\mathrm{TiO}_{2}$ Through their Precipitation in PVA Aqueous Solution," Carbon, 41 2619-24 (2003).

30. Y. Yu, J.C. Yu, J.G. Yu, Y.C. Kwok, Y.K. Che, J.C. Zhao, L. Ding, W.K. Ge, and P.K. Wang "Enhancement of Photocatalytic Activity of Mesoporous $\mathrm{Tio}_{2}$ by using Carbon Nanotubes," Appl. Cat. B: Environ, 289 186-96 (2005).

31. W.Wang, P. Serp, P. Kalck, C.G. Silvia, and J.L. Faria, "Preparation and Characterization of Nonostructured MWCNT-TiO ${ }_{2}$ Composite Materials for Photocatalytic Water Treatment Applications," Materials Research Bulletin, 43 958-67 (2008).

32. W.C. Oh, and M.L. Chen, "Synthesis and Characterization of $\mathrm{CNT} / \mathrm{TiO}_{2}$ Composites Thermally Derived from MWCNT and Titanium (IV) N-butoxide," Bull. Korean Chem. Soc., 29 [1] 159-64 (2008).

33. T. Matsunaga, and M. Inagaki, Proceeding of the 32nd annual meeting in Carbon Society of Japan, pp. 270-71, 2004.

34. M.L. Chen, F.J. Zhang, and W.C. Oh, "Photocatalytic degradation of Methylene Blue by $\mathrm{CNT} / \mathrm{TiO}_{2}$ Composites Prepared from MWCNT and Titanium N-butoxide with Benzene," J. Kor. Ceram. Soc., 45 [11] 651-57 (2008).

35. G. Cao, "Nanostructures \& Nanomaterials," pp. 344-5, Imperial College Press, 2004. 